\title{
Effects of Chungsinoryungsan, a polyherbal complex, on the pharmacokinetic profiles of perindopril in rats
}

\author{
SEOK-BONG KANG ${ }^{1 *}$, HO-SANG SHON ${ }^{2 *}$, SOO-JIN PARK ${ }^{3}$, CHANG-HYUN SONG $^{3}$ and SAE-KWANG KU ${ }^{3}$ \\ ${ }^{1}$ Department of Nephrology, College of Korean Medicine, Daegu Haany University, Gyeongsan, North Gyeongsang 712-715; \\ ${ }^{2}$ Department of Internal Medicine, Catholic University of Daegu, School of Medicine, Daegu 705-718; \\ ${ }^{3}$ Department of Anatomy and Histology, College of Korean Medicine, Daegu Haany University, \\ Gyeongsan, North Gyeongsang 712-715, Republic of Korea
}

Received June 23, 2014; Accepted July 30, 2014

DOI: $10.3892 /$ br.2014.330

\begin{abstract}
For sufficient antihypertension with less adverse effects, numerous clinical trials have recommended combination therapy using two or more hypertensive drugs. Chungsinoryungsan (CSORS) is a polyherbal complex based on oriental medicine, which has shown therapeutic potentials for antihypertension and additional renal improvement. Therefore, the affect of CSORS on the pharmacokinetic profiles of perindopril, an antihypertensive drug, was analyzed as a novel combination of hypertensive drugs. Rats received perindopril with CSORS as the combination or distilled water as the control. The co-administration of perindopril with CSORS or distilled water was performed by single dosing or repeated dosing for a week at a 2-h interval. The analyzed pharmacokinetic parameters included peak concentration $\left(\mathrm{C}_{\max }\right)$, time to reach the $\mathrm{C}_{\max }\left(\mathrm{T}_{\max }\right)$, area under the plasma concentration-time curve, terminal half-life $\left(\mathrm{t}_{1 / 2}\right)$ and mean residence time to infinity $\left(\mathrm{MRT}_{\mathrm{inf}}\right)$. In the single oral co-administration within $5 \mathrm{~min}$, the pharmacokinetics of perindopril demonstrated an increased $\mathrm{T}_{\max }$ and $\mathrm{MRT}_{\text {inf }}$ but reduced $t_{1 / 2}$ in the combination compared to the control treatment, indicating drug-drug interactions between perindopril and CSORS. However, in the repeated co-administration for a week at a 2-h interval, which was more than perindopril $\mathrm{MRT}_{\text {inf }}$ in the control treatment $(1.5 \pm 0.1 \mathrm{~h})$, the initial co-administration showed no differences in the pharmacokinetics between the combination and control treatments.
\end{abstract}

Correspondence to: Professor Sae-Kwang $\mathrm{Ku}$ or Professor Chang-Hyun Song, Department of Anatomy and Histology, College of Korean Medicine, Daegu Haany University, 1 Haanydaero Road, Gyeongsan, North Gyeongsang 712-715, Republic of Korea

E-mail: gucci200@hanmail.net

E-mail: dvmsong@hotmail.com

*Contributed equally

Key words: perindopril, pharmacokinetics, Chungsinoryungsan, natural product, polyherb, drug interaction
Furthermore, the repeated co-administration also showed no differences between the combination and control treatment. The results indicate that CSORS can be co-administered at a 2-h interval that was more than perindopril MRT $_{\text {inf }}$ and further clinical studies may provide detailed information for developing a drug regimen that generates enhanced combination effects of CSORS with hypertensive drugs.

\section{Introduction}

Hypertension is one of the most significant public issues with a high worldwide prevalence and its treatment can lead to reduced incidences of complications, such as stroke, myocardial infarction and renal disease (1). There are a number of antihypertensive drugs of various categories, including angiotensin-converting enzyme (ACE) inhibitors, calcium channel blockers, $\beta$-blockers and angiotensin II receptor antagonists. Thus far, clinical trials have indicated that monotherapy, the use of a single drug, is insufficient for achieving the goal blood pressure in patients with hypertension and ongoing trials have provided guidance on the appropriate combination regimens using $\geq 2$ antihypertensive drugs for increasing the synergic effects and reducing the unexpected adverse effects $(2,3)$. Furthermore, the combination regimens targeting functional improvement, as well as antihypertension, enhance the therapeutic effects even when the monotherapy is not evident in patients with renal dysfunction (4).

Perindopril is a long-acting ACE inhibitor that results in preventing the generation of angiotensin II in the renin-angiotensin-aldosterone system and subsequently lowering blood pressure. Numerous studies have revealed that perindopril is useful for treatment of hypertension (5), chronic heart failure (6) and diabetic nephropathies (7). Perindopril has good preclinical profiles with an $\mathrm{LD}_{50}$ at relatively high doses in various experimental animals (8), and clinical introduction and post-marketing surveillance studies have shown that perindopril is well-tolerated in a wide range of patients with hypertension (9). However, perindopril has a risk of severe hypotension despite low incidences and possible fetal and neonatal morbidity and mortality when used during pregnancy (9), indicating that the use of perindopril requires caution to avoid the unexpected adverse effects. 
Natural products have received increasing attention in the development of novel drug materials. There are a number of natural herbal products based on Korean medicine that have been adjusted from traditional Chinese medicine and the commercially available herbal drugs have been evaluated for novel combination regimens as an adjunctive medication (10). Wu Ling San (Oryungsan, ORS) known as a five-ingredient formula with poria, is the most famous nephroprotective Korean traditional polyherbal formula (11). The accumulated clinical trials have shown that ORS is useful for various diseases involved in hypertension, such as kidney diseases, cardiac edema, ascites, diabetes, liver cirrhosis and hydrocephalus. In addition, the therapeutic improvement has been revealed in experimental animal models of renal damage (12), nephrotic syndrome (13) and renal dysfunction (14). Chungsinoryungsan (CSORS) is based on the materials of ORS and 20 types of herb exhibiting nephroprotective effects are also added additionally (15). CSORS is indicated to possibly be useful in combination with antihypertensive drugs as an adjunctive medication. Therefore, the aim of the present study was to examine the drug-drug interactions between CSORS and perindopril via comprehensive pharmacokinetic analyses.

\section{Materials and methods}

Animals. Six-week-old male Sprague-Dawley rats (170-190 g) were obtained from Japan SLC, Inc. (Shizuoka, Japan). A total of 20 rats were separated randomly to five per polycarbonate cage and acclimatized in a room controlled at $20-25^{\circ} \mathrm{C}$ and $40-45 \%$ humidity for 2 weeks. The rats were maintained on a 12-h light/dark cycle with free access to standard rodent chow and water. All the experimental procedures were approved by the Institutional Animal Care and Use Committee at Daegu Haany University (Gyeongsan, Korea).

Drugs and treatment. Perindopril was purchased from Panaaya Pharma Private, Ltd. (Hyderabad, India). CSORS was prepared at the Department of Herbology (College of Korean Medicine, Daegu Haany University). For producing CSORS, 25 types of herb were purchased from Jecheon Hanbang Yakcho (Jecheon, Korea) following confirmation of the complete morphology under microscopy (Table I). The herbs $(1,420 \mathrm{~g})$ were boiled in 21 distilled water for $3 \mathrm{~h}$, three times at $80^{\circ} \mathrm{C}$ and subsequently filtered. The resultant filtrate was decompressed with a rotary vacuum evaporator (Rotavapor R-144; Buchi, Flawil, Switzerland) and lyophilized in a programmable freeze dryer (FreeZone 1 Liter Benchtop; Labconco Corporation, Kansas City, MO, USA). Eventually, the acquired CSORS extract volume was $173.24 \mathrm{~g}$ as a light brown powder (yield, 12.2\%). The perindopril and CSORS drugs were stored as a powder at $4^{\circ} \mathrm{C}$ in the dark until required.

One batch of 10 rats received single oral dosing of perindopril combination with CSORS (combination group) or perindopril with distilled water (control) and another batch of 10 rats received repeated oral dosing of combination and control once a day for a week. The co-administration with CSORS or distilled water was performed by the single dosing within 5 min after perindopril, or the repeated dosing at a 2-h interval after perindopril. The drug dosing was a volume of $5 \mathrm{ml} / \mathrm{kg}$ at $100 \mathrm{ml} / \mathrm{kg}$ CSORS and $50 \mathrm{mg} / \mathrm{kg}$ perindopril, based on its toxicity and clinical database (8). Body weights were measured prior to every administration using an automatic electronic balance (Precisa Instruments AG, Dietikon, Switzerland).

Collection of blood samples and sample preparation. The rats were fasted overnight a day before collection of the blood sample to avoid dietary effects. The blood sample via the retro-orbital route was collected in anticoagulant tubes, including 50 IU heparin, at $0.5 \mathrm{~h}$ prior to the administration and $0.5,1,2,3$, $4,6,8$ and $24 \mathrm{~h}$ post-administration. The plasma sample was centrifuged at $11,400 \mathrm{x}$ g for $10 \mathrm{~min}$ and the supernatant aliquot was stored at $-70^{\circ} \mathrm{C}$ until pharmacokinetic analyses.

Sample preparation and calibrations. For a calibration, $1.0 \mathrm{mg} / \mathrm{ml}$ perindopril (Sigma, St. Louis, MO, USA) diluted with $50 \%$ acetonitrile was used as a primary stock solution and $500 \mathrm{ng} / \mathrm{ml}$ carbamazepine (Sigma) in acetonitrile was used as an internal standard (IS) solution. The working standard solutions were prepared by dilution of the primary stock solution with acetonitrile and stored in the dark at $-20^{\circ} \mathrm{C}$. The $100 \mu \mathrm{l}$ working standard solutions were mixed with $100 \mu \mathrm{l}$ blank plasma and IS solutions in $100 \mu$ l acetonitrile for the perindopril concentration standard curve. The $100-\mu 1$ plasma sample was prepared as a mixture with $100-\mu 1$ IS solution in $200 \mu \mathrm{l}$ acetonitrile. The mixtures were centrifuged at 9,700 $\mathrm{xg}$ for $10 \mathrm{~min}$ at $4^{\circ} \mathrm{C}$ and the supernatant was transferred to injection vials for liquid chromatography-mass spectrometry/mass spectrometry (LC-MS/MS).

LC-MS/MS conditions. Chromatographic analysis was performed using an Agilent 1100 series HPLC (Agilent Technologies, Santa Clara, CA, USA) equipped with online degasser, binary pump, auto-sampler, column compartment and column oven at $30^{\circ} \mathrm{C}$. Separation of the analyte from potentially interfering material was achieved using Waters XTerra MS C18 columns $(2.1 \times 50 \mathrm{~mm}, 3.5 \mu \mathrm{m})$ (Waters Corporation, Milford, MA, USA). The mobile phase for chromatographic separation was composed of 5-95\% acetonitrile, including $0.1 \%$ formic acid, and it was delivered isocratically at a flow rate of $0.3 \mathrm{ml} / \mathrm{min}$. The column effluent was monitored using an API 2000 triple quadrupole mass-spectrometer detector (Applied Biosystems, Foster City, CA, USA). The instrument was equipped with an electrospray interface in positive-ion mode, which was controlled by the Analyst version 1.4.2 software (Applied Biosystems). The samples were introduced to the interface through turbo ionspray at $400^{\circ} \mathrm{C}$. A high positive voltage of $5.0 \mathrm{kV}$ was applied to the ion spray. Nitrogen was used as nebulizer gas, curtain gas and collision gas with sets of 12, 6 and 8 PSI, respectively. The multiple reaction monitoring detection method was employed for the detection of perindopril; the transitions monitored were carbamazepine (IS): m/z 237>194 (retention time, $2.7 \mathrm{~min}$ ); and perindopril: 369>172 (retention time, $2.5 \mathrm{~min}$ ). Calibration curves of perindopril were linear over the ranges with $r^{2}>0.999$. The lower limit of quantification was $0.1 \mathrm{ng} / \mathrm{ml}$.

Pharmacokinetic analyses. The perindopril concentration in plasma was analyzed using a non-compartmental method 
Table I. Twenty five types of herb consisting of Chungsinoryungsan aqueous extracts.

\begin{tabular}{|c|c|c|}
\hline Herbs & Scientific names/produce region & Amounts, $g$ \\
\hline Alismatis rhizoma & Alisma orientale (Sam.) Juz./Chunnam & 100 \\
\hline Tokoro rhizoma & Dioscorea tokoro Makino/China & 100 \\
\hline Alpiniae fructus & Alpinia oxyphylla Miquel/China & 80 \\
\hline Polyporus & Dendropolyporus umbellatus (Pers.:Fr.) Jülich/China & 80 \\
\hline Hoelen & Poria cocos Wolf//China & 80 \\
\hline Dioscoreae rhizoma & Dioscorea batatus Decne./Kyungbuk & 80 \\
\hline Astragali radix & Astragalus membranaceus Bunge/Chungbuk & 60 \\
\hline Mantidis ootheca & Paratenodera sinensis De Saussure/China & 60 \\
\hline Atractylodis rhizoma alba & Atractylodes ovata (Thunb.) DC./China & 60 \\
\hline Nelumbinis semen & Nelumbo nucifera Gaertn./China & 60 \\
\hline Acori Gramineri rhizoma & Acorus gramineus Soland./China & 60 \\
\hline Artemisiae capillaris herba & Artemisia capillaris Thunberg/Kyungbuk & 60 \\
\hline Plantaginis semen & Plantago asiatica L./China & 60 \\
\hline Amomi fructus & Amomum villosum Loureiro var. xanthioides T.L.Wu et Senjen/China & 60 \\
\hline Remotiflori radix & Adenophora remotiflora (Siebold and Zucc.) Miq. /China & 60 \\
\hline Citri unshii pericarpium & Citrus unshiu S.Marcov./Cheju & 40 \\
\hline Fossilia ossis mastodi & Fossilia ossis mastodi/China & 40 \\
\hline Terminaliae fructus & Terminalia chebula Retz./China & 40 \\
\hline Ginseng radix alba & Panax ginseng C.A.Meyer/Chungnam & 40 \\
\hline Cimicifugae rhizoma & Cimicifuga heracleifolia Kom./China & 40 \\
\hline Aurantii immaturus fructus & Citrus aurantium L./China & 40 \\
\hline Myristicae semen & Myristica fragrans Houtt./China & 40 \\
\hline Pulvis ostreae testa & Crassostrea gigas Thunberg/China & 30 \\
\hline Cinnamomi cortex & Cinnamomum cassia J. Presl./China & 30 \\
\hline Mume fructus & Prunus mume Siebold et Zuccarini/China & 20 \\
\hline
\end{tabular}

All the individual herbs were purchased from the Local Pharmacy of Oriental Medicine (Jecheon, Korea) at the indicated amounts.

on the commercial pharmacokinetics data analyzer program (PK Solutions 2.0; Summit Research Services, Montrose, CO, USA) (16). The elimination rate constant $\left(\mathrm{K}_{\mathrm{el}}\right)$ was calculated by log-linear regression of perindopril concentration data during the elimination phase, and the terminal half-life $\left(\mathrm{t}_{1 / 2}\right)$ was calculated by $0.693 / \mathrm{K}_{\mathrm{el}}$. The peak concentration $\left(\mathrm{C}_{\max }\right)$ of plasma perindopril and time to reach the $\mathrm{C}_{\max }\left(\mathrm{T}_{\max }\right)$ were obtained by visual inspection in the concentration-time curve. The area under the perindopril concentration-time curve $\left(\mathrm{AUC}_{0-\mathrm{t}}\right)$ from time zero to the time of the measured concentration $\left(\mathrm{C}_{\text {last }}\right)$ was calculated using the linear trapezoidal rule (17). The AUC zero to infinity $\left(\mathrm{AUC}_{0 \text {-inf }}\right)$ was obtained by adding $\mathrm{AUC}_{0-\mathrm{t}}$ and the extrapolated area was determined by $\mathrm{C}_{\text {last }} / \mathrm{K}_{\mathrm{el}}$. The mean residence time to infinity ( $\mathrm{MRT}_{\mathrm{inf}}$ ) was calculated by dividing the first moment curve $\left(\mathrm{AUMC}_{0 \text {-inf }}\right)$ by $\mathrm{AUC}_{0 \text {-inf }}$.

Statistical analyses. All the data are presented as average values \pm standard error of the mean (SEM). Data for body weights and perindopril concentration were examined by testing the homogeneity of variance, followed by analysis of variance (ANOVA) with the group as a main effect. The day on which the body weights were measured or the time collected for plasma samples was treated as repeated measurements. When the data passed at the test of homogeneity of variance, they were compared by independent t-test for post hoc test, otherwise, the data were compared by Mann-Whitney U test. All the pharmacokinetic parameters were examined by Mann-Whitney $U$ test as a non-parametric comparison due to the small sample sizes, which have difficulties reaching a normal distribution. For all analyses, $\mathrm{P}<0.05$ was considered to indicate a statistically significant difference.

\section{Results}

Single oral administration of perindopril combination with CSORS within 5 min

Body weight changes. There were no differences in the body weights between the combination and control treatment $(\mathrm{F}=0.02, \mathrm{P}>0.10)$. The weight changes were $26.0 \pm 1.5$ and $27.6 \pm 1.0 \mathrm{~g}$ in the combination and control groups, respectively.

Perindopril concentration. Perindopril was detected until $8 \mathrm{~h}$ post-administration in the combination treatment, whereas it was detected until $4 \mathrm{~h}$ in the control treatment (Fig. 1). The kinetics of perindopril concentration were examined by ANOVA with the group as a main effect and the collected time was treated as a repeated measurement. Overall, there were significant main effects for time $(\mathrm{F}=143.8, \mathrm{P}<0.01)$, indicating time-dependent perindopril concentration. Although no main effects for group were found $(\mathrm{F}=0.3, \mathrm{P}>0.10)$, there 
Table II. Body weight changes following repeated administration of perindopril combination with Chungsinoryungsan for a week at a 2-h interval.

\begin{tabular}{lrr}
\hline & \multicolumn{2}{c}{ Body weight $(\mathrm{g})$} \\
\cline { 2 - 3 } Perindopril combination & Distilled water & \multicolumn{1}{c}{ CSORS } \\
\hline Initial co-administration [A] & $227.4 \pm 2.8$ & $227.8 \pm 6.0$ \\
Last co-administration [B] & $248.2 \pm 3.6$ & $248.0 \pm 4.6$ \\
Changes [B]-[A] & $20.8 \pm 2.7$ & $20.2 \pm 2.3$ \\
\hline
\end{tabular}

Data represent average values $(\mathrm{g}) \pm \mathrm{SEM}$ in combination group [perindopril with Chungsinoryungsan (CSORS)] and control (periondopril with distilled water) following the initial and last co-administration of a repeated dosing for a week at a 2-h interval.

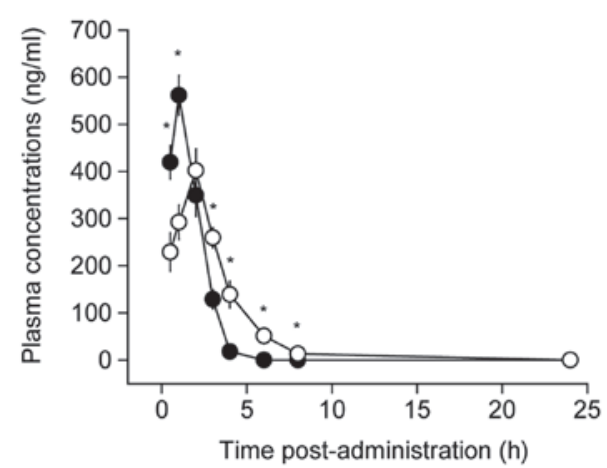

Figure 1. Plasma perindopril concentration in combination with Chungsinoryungsan (CSORS) within $5 \mathrm{~min}$. The combination group of rats received oral co-administration of perindopril with CSORS within 5 min (open circles, $\mathrm{n}=5$ ) and the corresponding control received perindopril with distilled water (closed circles, $\mathrm{n}=5$ ). The plasma samples were assessed at 0.5 , $1,2,3,4,6,8$ and $24 \mathrm{~h}$ post-administration. All the data represent average values $(\mathrm{ng} / \mathrm{ml}) \pm \mathrm{SEM}$. ${ }^{*} \mathrm{P}<0.01$.

were significant interactions between time and group $(\mathrm{F}=24.0$, $\mathrm{P}<0.01)$. Post hoc test revealed that the combination treatment reduced the perindopril concentration by $55 \%$ at $0.5 \mathrm{~h}$ post-administration and $52 \%$ at $1 \mathrm{~h}$, and increased by 202,771 , 613 and $231 \%$ at 3, 4, 6 and $8 \mathrm{~h}$, respectively, compared to the control $(\mathrm{P}<0.01)$ (Fig. 1). This indicates altered perindopril pharmacodynamics by CSORS.

Perindopril pharmacokinetics. Although it was not significant $(\mathrm{P}=0.06)$, for group analysis the $\mathrm{C}_{\max }$ showed a $28 \%$ reduction in the combination $(401.9 \pm 41.9 \mathrm{ng} / \mathrm{ml})$ compared to the control treatment $(561.5 \pm 46.0 \mathrm{ng} / \mathrm{ml})$ (Fig. 2A). However, there were significant main effects for group for $\mathrm{T}_{\max }(\mathrm{P}<0.01)$ and $\mathrm{t}_{1 / 2}(\mathrm{P}<0.01)$ (Fig. $2 \mathrm{~B}$ and $\left.\mathrm{C}\right)$. $\mathrm{T}_{\max }$ for the combination group was increased by $200 \%$ compared to the control and $\mathrm{t}_{1 / 2}$ was reduced by $60 \%$. $\mathrm{T}_{\max }$ was $2.0 \pm 0.0$ vs. $1.0 \pm 0.0 \mathrm{~h}$ in the combination versus the control treatment and $\mathrm{t}_{1 / 2}$ was $0.59 \pm 0.03 \mathrm{~h}$ vs. $1.47 \pm 0.15 \mathrm{~h}$, respectively. $\mathrm{AUC}_{0-\mathrm{t}}$ of perindopril was not significantly increased in the combination $(1,319.6 \pm 160.4 \mathrm{ng} \mathrm{h} / \mathrm{ml})$ compared to the control group $(1,117.9 \pm 82.5 \mathrm{ng} \mathrm{h} / \mathrm{ml})(\mathrm{P}>0.10)$ (Fig. 2D). No differences were detected in $\mathrm{AUC}_{0 \text {-inf }}$ between the groups $(\mathrm{P}>0.10)$ (Fig. 2E). However, $\mathrm{MRT}_{\text {inf }}$ was significantly increased by $78 \%$ in the combination $(2.7 \pm 0.1 \mathrm{~h})$ compared to the control treatment $(1.5 \pm 0.0 \mathrm{~h})(\mathrm{P}<0.01)$ (Fig. 2F). These results indicate delayed absorption and excretion of perindopril by combination with CSORS within 5 min.

Repeated oral administration of perindopril combination with CSORS for a week at a 2-h interval

Body weight changes. No evident differences were found in the gross aspects of behavior and weight changes (Table II). ANOVA revealed no main effects for the group $(\mathrm{F}=0.001, \mathrm{P}>0.10)$ and no interactions between group and measured days $(\mathrm{F}=0.2, \mathrm{P}>0.10)$.

Perindopril concentration. Following the initial and last co-administration, the perindopril was detected up until $4 \mathrm{~h}$ post-administration in the combination and control groups (Fig. 3). The time-concentration graph was similar between the combination and control groups. Following the initial co-administration (Fig. 3A), there were significant main effects for time $(\mathrm{F}=185.3, \mathrm{P}<0.01)$, but no main effects for group $(\mathrm{F}=0.1, \mathrm{P}>0.10)$ and no interaction between time and group $(\mathrm{F}=0.1, \mathrm{P}>0.10)$. Following the last co-administration of the repeated administration (Fig. 3B), there were significant main effects for time $(\mathrm{F}=205.3, \mathrm{P}<0.01)$, but no main effects for group $(\mathrm{F}=0.07, \mathrm{P}>0.10)$ and no interaction between time and group $(\mathrm{F}=0.04, \mathrm{P}>0.10)$. These indicate limited interaction between perindopril and CSORS by co-administration at a 2-h interval.

Perindopril pharmacokinetics. The perindopril combination with CSORS at a 2-h interval showed no differences in $\mathrm{T}_{\max }, \mathrm{C}_{\max }, \mathrm{t}_{1 / 2}, \mathrm{AUC}_{0-\mathrm{t}}, \mathrm{AUC}_{0 \text {-inf }}$ and $\mathrm{MRT}_{\text {inf }}$ compared to the control following the initial and last co-administration of the repeated administration for a week (Fig. 4). Mann-Whitney $\mathrm{U}$ test revealed no main effects for group for any of the parameters assessed $(\mathrm{P}>0.10)$.

\section{Discussion}

The effects of CSORS administration on pharmacokinetics of perindopril were examined in the present study. When perindopril was co-administered with CSORS within $5 \mathrm{~min}$, the perindopril plasma concentration was different from the normal pharmacokinetics of the control (Fig. 1). The pharmacokinetic parameters showed reduced $t_{1 / 2}$ and increased $T_{\max }$ and $\mathrm{MRT}_{\text {inf }}$ in the combination compared to the control group. This indicates a drug-drug interaction between perindopril and CSORS (Fig. 2). Perindopril was hypothesized to possibly have a limited interaction with CSORS co-administration at an interval gap that was more than perindopril $\mathrm{MRT}_{\text {inf }}$ of the control treatment $(1.51 \pm 0.09 \mathrm{~h})$. When perindopril was co-administered with CSORS at a 2-h interval, the perindopril concentration and pharmacokinetic parameters were not different between the combination and control groups following the initial and last administration of a weekly repeated dosing (Figs. 3 and 4). These results provide detailed information for the drug regimen of perindopril combination with CSORS.

Perindopril has been shown to have various drug-drug interactions with diuretics $(18,19)$, gentamicin $(20)$ and lithium $(21,22)$. However, there have been limited studies regarding the interactions between perindopril and natural 

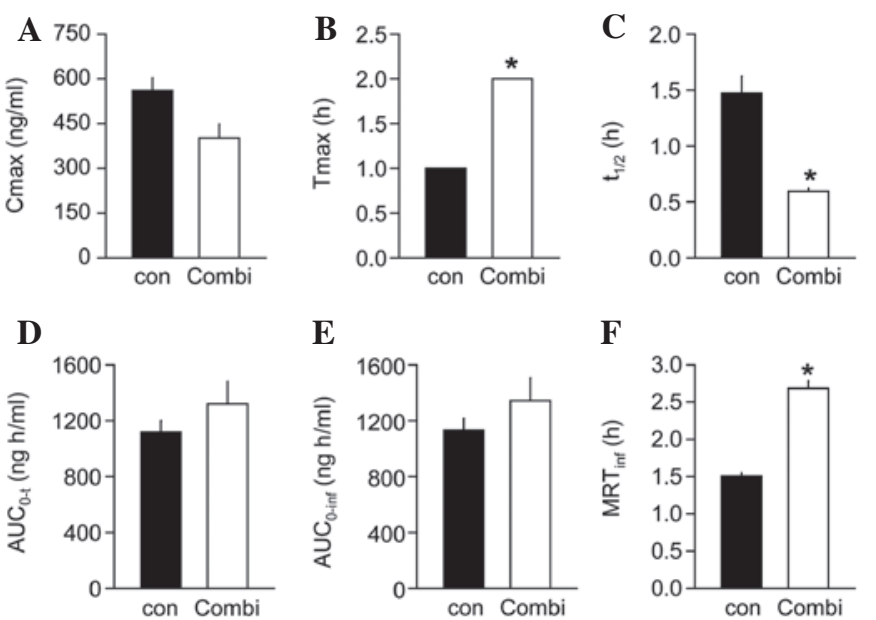

Figure 2. Pharmacokinetic profiles of perindopril in combination with Chungsinoryungsan within 5 min. The plasma samples used in Fig. 1 were subjected to analyses of pharmacokinetic parameters: (A) Peak concentration $\left(\mathrm{C}_{\max }\right),(\mathrm{B})$ time to reach the $\mathrm{C}_{\max }\left(\mathrm{T}_{\max }\right),(\mathrm{C})$ terminal half-life $\left(\mathrm{t}_{1 / 2}\right),(\mathrm{D})$ area under the perindopril concentration-time curve $\left(\mathrm{AUC}_{0-t}\right),(\mathrm{E}) \mathrm{AUC}$ zero to infinity $\left(\mathrm{AUC}_{0 \text {-inf }}\right)$ and $(\mathrm{F})$ mean residence time to infinity $\left(\mathrm{MRT}_{\text {inf }}\right)$. Each graph represents average values \pm SEM in the combination (Combi, white bars) and control (con, black bars). ${ }^{*} \mathrm{P}<0.01$.
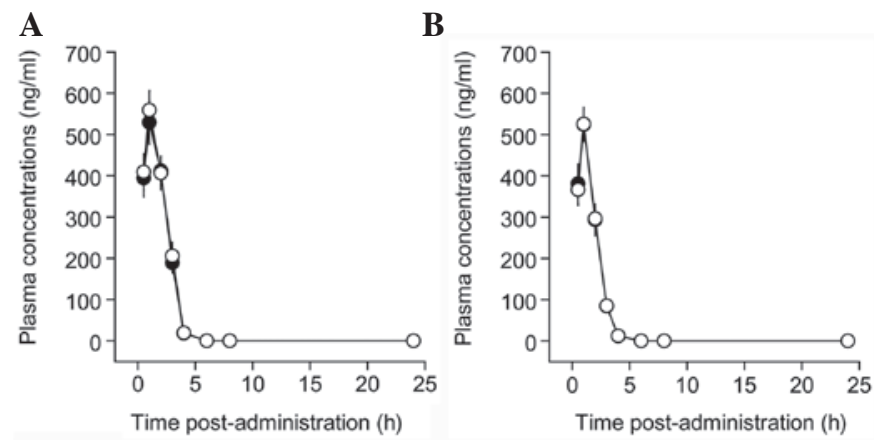

Figure 3. Plasma perindopril concentration in combination with Chungsinoryungsan (CSORS) at 2 -h interval. The combination group received a repeated co-administration of perindopril in combination with CSORS for a week at 2-h interval (open circles, $\mathrm{n}=5$ ) and the corresponding control received perindopril with distilled water (closed circles, $n=5$ ). The plasma samples were assessed at $0.5,1,2,3,4,6,8$ and $24 \mathrm{~h}$ after (A) the initial and (B) last co-administration of the repeated dosing. All the data represent average values $(\mathrm{ng} / \mathrm{ml}) \pm \mathrm{SEM}$.

herbal products, except for digoxin $(23,24)$. In the present study, single oral administration of perindopril combination with CSORS within 5 min markedly delayed the absorption of perindopril and its excretion, whereas the co-administration of the combination at a 2-h interval showed no interaction between perindopril and CSORS even by a weekly repeated dosing. Perindopril is well-absorbed in the gastrointestinal tract with a high bioavailability of $75 \%$ via the oral route (25), however, it is extensively metabolized to six metabolites, including perindoprilat, an active metabolite, in the liver $(26,27)$. The maximal concentration of plasma perindoprilat is reached 2-6 h after oral administration of perindopril and $70 \%$ of perindoprilat is cleared by the kidneys. Food does not influence the rate or extent of perindopril absorption but reduces conversion to perindoprilat by $\sim 35 \%$ (28). The present study results showed a $\mathrm{T}_{\max }$ of $1 \mathrm{~h}$ in the control group, which
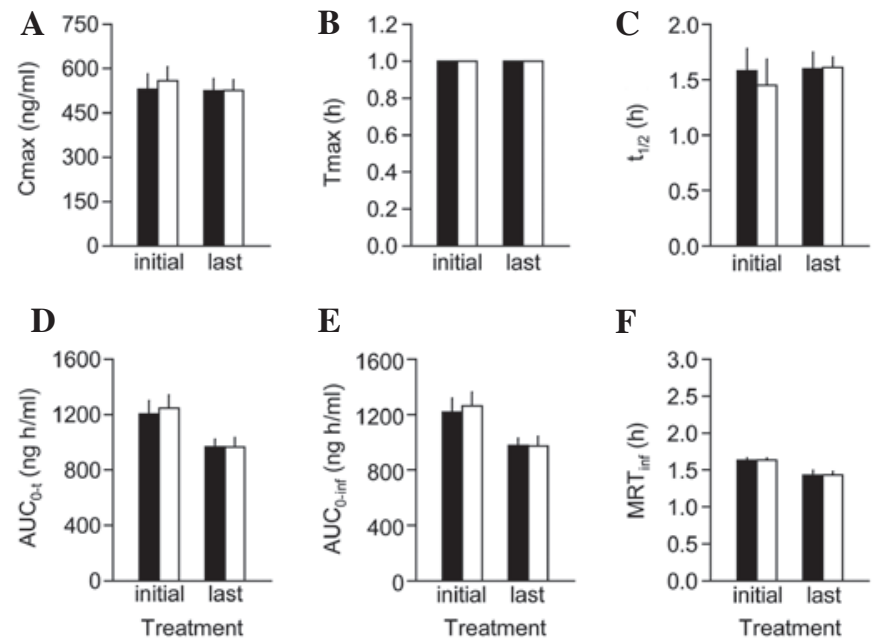

Figure 4. Pharmacokinetic profiles of perindopril in combination with Chungsinoryungsan at 2-h interval. The plasma samples used in Fig. 3 were subjected to analyses of pharmacokinetic parameters: (A) Peak concentration $\left(\mathrm{C}_{\max }\right),(\mathrm{B})$ time to reach the $\mathrm{C}_{\max }\left(\mathrm{T}_{\max }\right),(\mathrm{C})$ terminal half-life $\left(\mathrm{t}_{1 / 2}\right),(\mathrm{D})$ area under the perindopril concentration-time curve $\left(\mathrm{AUC}_{0-t}\right),(\mathrm{E}) \mathrm{AUC}$ zero to infinity $\left(\mathrm{AUC}_{0 \text {-inf }}\right)$ and $(\mathrm{F})$ mean residence time to infinity $\left(\mathrm{MRT}_{\text {inf }}\right)$. The corresponding data represent average values \pm SEM in the combination group (white bars) and control (black bars) after the initial and last co-administration of repeated dosing for a week.

had a similarity with that of humans (Figs 2B and 4B) (26). However, perindopril combination with CSORS within 5 min resulted in $2 \mathrm{~h}$ of $\mathrm{T}_{\max }$. Although the exact mechanism regarding how CSORS interacted with perindopril is unclear, it may be due to partial interruption of perindopril absorption by coexistence with CSORS or delayed conversion of perindopril to perindoprilat.

In the present study, CSORS had no interaction with perindopril in a weekly repeated co-administration at 2-h intervals, which indicates the suitable dosing regimen for the combination therapy. However, there are numerous clinical factors that alter perindopril pharmacokinetics. Since the active metabolites of perindopril are hydrolyzed in the liver and primarily excreted into the urine, the elimination kinetics can be altered in hepatic impairment (26,29), renal failure (30) or chronic heart failure (31). Ageing is also associated with the alteration in enhanced conversion to perindoprilat and the reduced renal clearance (32). Therefore, perindopril combination therapy requires further clinical studies for the pharmacokinetics in specific disease conditions. To the best of our knowledge, this is the first study to monitor the use of CSORS in combination with antihypertensive drugs. The results showed CSORS co-administration has limited interaction with perindopril at an interval that was more than mean residence time of perindopril. These results provide detailed information for a drug dosing regimen of perindopril with CSORS in human clinical studies of novel combination therapy.

\section{Acknowledgements}

The present study was supported in part by grant of Korea of Health and Welfare, Republic of Korea (grant no. 20-11-0-090 -091-3000-3033-320). 


\section{References}

1. Kearney PM, Whelton M, Reynolds K, Whelton PK and He J: Worldwide prevalence of hypertension: a systematic review. J Hypertens 22: 11-19, 2004.

2. Nesbitt SD: Antihypertensive combination therapy: optimizing blood pressure control and cardiovascular risk reduction. J Clin Hypertens (Greenwich) 9 (Suppl 4): 26-32, 2007.

3. Salahuddin A, Mushtaq M and Materson BJ: Combination therapy for hypertension 2013: an update. J Am Soc Hypertens 7: 401-407, 2013.

4. Nakao N, Yoshimura A, Morita H, Takada M, Kayano T and Ideura T: Combination treatment of angiotensin-II receptor blocker and angiotensin-converting-enzyme inhibitor in non-diabetic renal disease (COOPERATE): a randomised controlled trial. Lancet 361: 117-124, 2003.

5. Todd PA and Fitton A: Perindopril. A review of its pharmacological properties and therapeutic use in cardiovascular disorders. Drugs 42: 90-114, 1991.

6. Cleland JG, Tendera M, Adamus J, et al: The perindopril in elderly people with chronic heart failure (PEP-CHF) study. Eur Heart J 27: 2338-2345, 2006.

7. Waeber B, de la Sierra A and Ruilope LM: The ADVANCE trial: clarifying the role of perindopril/indapamide fixed-dose combination in the reduction of cardiovascular and renal events in patients with diabetes mellitus. Am J Cardiovasc Drugs 9: 283-291, 2009.

8. Santa Cruz Biotechnology: Material safety data sheet of perindopril (sc-205799). http://pdf.analysis1.org/perindopril-santacruz-biotechnology-w1778. Accessed on December 6, 2010.

9. Clark LT: Safety profile of perindopril. Am J Cardiol 88: 36i-40i, 2001.

10. Ji HF, Li XJ and Zhang HY: Natural products and drug discovery. Can thousands of years of ancient medical knowledge lead us to new and powerful drug combinations in the fight against cancer and dementia? EMBO Rep 10: 194-200, 2009.

11. Scheid V, Bensky B, Ellis A and Barolet R: Chinese Herbal Medicine: Formulas and Strategies. 2nd edition. Eastland Press, Seattle, WA, pp724-728, 2009.

12. Liu IM, Tzeng TF, Liou SS and Chang CJ: The amelioration of streptozotocin diabetes-induced renal damage by Wu-Ling-San (Hoelen Five Herb Formula), a traditional Chinese prescription. J Ethnopharmacol 124: 211-218, 2009.

13. He L, Rong X, Jiang JM, Liu PQ and Li Y: Amelioration of anticancer agent adriamycin-induced nephrotic syndrome in rats by Wulingsan (Gorei-San), a blended traditional Chinese herbal medicine. Food Chem Toxicol 46: 1452-1460, 2008.

14. Ding XQ, Pan Y, Wang X, Ma YX and Kong LD: Wuling san ameliorates urate under-excretion and renal dysfunction in hyperuricemic mice. Chin J Nat Med 11: 214-221, 2013.

15. Zhu YP (ed): Chinese Materia Medica: Chemistry, Pharmacology, and Applications. Harwood Academic, Amsterdam, pp311-344, 1998.

16. DeVane CL: Pharmacokinetics (2nd edition, revised and expanded), M. Gibaldi and D. Perrier (vol. 15 of Drugs and the Pharmaceutical sciences), Marcel Dekker, New York, 1982. Biopharmaceutics and Drug Disposition 4: 201-201, 1983.

17. Chiou WL: Critical evaluation of the potential error in pharmacokinetic studies of using the linear trapezoidal rule method for the calculation of the area under the plasma level - time curve. J Pharmacokinet Biopharm 6: 539-546, 1978.
18. Brown CL, Backhouse CI, Grippat JC and Santoni JP: The effect of perindopril and hydrochlorothiazide alone and in combination on blood pressure and on the renin-angiotensin system in hypertensive subjects. Eur J Clin Pharmacol 39: 327-332, 1990.

19. Scalbert E, Abdon D, Devissaguet $M$ and Juggi JS: Interaction between an angiotensin converting enzyme inhibitor, perindopril, and a thiazide diuretic in the spontaneously hypertensive rat. Can J Cardiol 8: 381-386, 1992.

20. Morin JP, Thomas N, Toutain H, Borghi H and Fillastre JP: Treatment with an angiotensin converting enzyme inhibitor may increase the nephrotoxicity of gentamicin in rats. Pathol Biol (Paris) 37: 652-656, 1989 (In French).

21. Vipond AJ, Bakewell S, Telford R and Nicholls AJ: Lithium toxicity. Anaesthesia 51: 1156-1158, 1996.

22. Christensen S, Shalmi M, Hansen AK and Marcussen N: Effects of perindopril and hydrochlorothiazide on the long-term progression of lithium-induced chronic renal failure in rats. Pharmacol Toxicol 80: 132-141, 1997.

23. Vandenburg MJ, Stephens JD, Resplandy G, Dews IM, Robinson J and Desche P: Digoxin pharmacokinetics and perindopril in heart failure patients. J Clin Pharmacol 33: 146-149, 1993.

24. Johnston D and Duffin D: Drug-patient interactions and their relevance in the treatment of heart failure. Am J Cardiol 70: 109C-112C, 1992.

25. Setiawati E, Deniati SH, Yunaidi DA, et al: Bioequivalence study of two perindopril erbumine tablet formulations in healthy volunteers. Arzneimittelforschung 61: 234-238, 2011.

26. Devissaguet JP, Ammoury N, Devissaguet M and Perret L: Pharmacokinetics of perindopril and its metabolites in healthy volunteers. Fundam Clin Pharmacol 4: 175-189, 1990.

27. Georgakakou S, Kazanis M and Panderi I: Hydrophilic interaction liquid chromatography/positive ion electrospray ionization mass spectrometry method for the quantification of perindopril and its main metabolite in human plasma. Anal Bioanal Chem 397: 2161-2170, 2010.

28. Lecocq B, Funck-Brentano C, Lecocq V, et al: Influence of food on the pharmacokinetics of perindopril and the time course of angiotensin-converting enzyme inhibition in serum. Clin Pharmacol Ther 47: 397-402, 1990.

29. Grislain L, Mocquard MT, Dabe JF, et al: Interspecies comparison of the metabolic pathways of perindopril, a new angiotensin-converting enzyme (ACE) inhibitor. Xenobiotica 20: 787-800, 1990 .

30. Begg EJ, Robson RA, Bailey RR, Lynn KL, Frank GJ and Olson SC: The pharmacokinetics and pharmacodynamics of quinapril and quinaprilat in renal impairment. Br J Clin Pharmacol 30: 213-220, 1990.

31. Resplandy G and Genissel P: Pharmacokinetics of perindopril in high-risk populations. J Cardiovasc Pharmacol 18 (Suppl 7): S9-S18, 1991.

32. Parker E, Aarons L, Rowland M and Resplandy G: The pharmacokinetics of perindoprilat in normal volunteers and patients: influence of age and disease state. Eur J Pharm Sci 26: 104-113, 2005. 